\title{
O JOGO ENTRE SIMULAÇÃO E REPRESENTAÇÃO NA NARRATIVA PÓS-MODERNA
}

\author{
Noeme da Piedade Lima Klingl*
}

RESUM0:

\begin{abstract}
O trabalho descreve aspectos da escrita pós-moderna como um efeito do diálogo estabelecido com as tecnologias de comunicação e de informação das últimas décadas. Ele também examina o regime ontológico que preside a relação estabelecida entre a realidade e as obras de arte marcadas pela sobrecarga e pela disseminação de referências culturais.

PALAVRAS-CHAVE: pós-modernismo, referências culturais, tecnologias de comunicação e de informação, simulação, representação.
\end{abstract}

Uma vertente da narrativa da atualidade deixa-se ler em termos da reelaboração estética do ambiente eletrônico que permeia as diversas esferas da realidade de hoje, como parte de uma revolução tecnológica comparável à da imprensa, na Renascença. Para descrever e analisar algumas das implicações mais significativas do diálogo entre a prosa literária pós-moderna e o aparato eletrônico da contemporaneidade pode-se tomar 0 arco-íris da gravidade - romance publicado em 1973 pelo autor norte-americano Thomas Pynchon - como corpus básico para relações com autores das últimas décadas, com Ricardo Piglia, Italo Calvino e Salmon Rushdie entre eles.

Observa-se que se tem aí uma textualidade marcada pela apropriação e desapropriação de uma matéria heteróclita - empréstimos tomados de obras da alta literatura, da cultura popular e de massa (filmes, best sellers, jornais, revistas em quadrinhos, por exemplo) ao lado de recortes de clássicos das mais variadas áreas

| Doutora em Letras: Estudos Literários (Ārea de concentração: Literatura Comparada), 2003. 


\section{EMTESE}

Belo Horizonte, v. 8, p. I-243, dez. 2004

do conhecimento e de obras de sua divulgação. Compõe-se, assim, uma narrativa em que é decisivo o papel do leitor, a quem cabe a articulação de fragmentos, nos quais sobressaem as referências culturais que saturam o espaço da escrita.

Ao assumir tal delineamento, o texto realiza o conceito operatório de um arquivo: desempenha as funções de armazenamento e reprocessamento de dados que - uma vez tomados de fontes da memória cultural - são assim submetidos às operações de conservação, de ordenamento e de recuperação. A escrita mescla saberes, fazendo uso da "tradição" - conceito proposto por Gianni Vattimo (Vattimo: 1987, 27) para a "transmissão e a interpretação de mensagens que as linguagens trazem do passado e de outras culturas". Inserido nesse contexto da cultura contemporânea - para cujo estabelecimento é decisivo o papel dos meios de comunicação e de informação - o texto se inscreve na pós-modernidade, conceito que se deve tomar, em sintonia com aquele pensador italiano, como ligado à crise de metafísica, de modo específico ao estatuto "frágil" da verdade, construída a partir de uma agonística geral da linguagem. Tal conceituação exibe estreita afinidade com o pensamento de Jean François Lyotard (Lyotard: 1988 58-76), para quem a condição pós-moderna se instaura a partir da deslegitimação dos grandes relatos da modernidade, o da especulação o discurso da ciência - e o da emancipação, que afirma como telos do primeiro a promoção da Aufklärung, então vista como o poder do Estado para a formação do "povo", sob a forma política de nação, e sua orientação no caminho do progresso. A perda de credibilidade dessas metanarrativas da modernidade ocorre à medida que passam a ser vistas como construídas por atos de fala específicos.

Deve-se fazer a distinção entre o delineamento pós-moderno de arquivo e o modelo anterior: na escrita de hoje, em interlocução com a memória técnica do aparato eletrônico, o leitor não somente liga as referências culturais de modo a construir linhas de sentido que atravessam o espaço textual. Nele, além de a leitura se dar como o estabelecimento de percursos enunciativos, há o deslizamento, com escape do sentido entre eles. Em outras palavras, ocorre a desconstrução da informação, que não emerge ordenada tal como no arquivo tradicional. No delineamento contemporâneo, a taxionomia é vazada e instável. Gera-se uma significação cambiante, com zonas de indeterminação de que o leitor não pode dar conta.

0 resultado pode ser descrito com base nas reflexões desenvolvidas por Michel Foucault no prefácio de As palavras e as coisas, a respeito de uma enciclopédia 
chinesa a que Jorge Luis Borges no se refere conto "0 idioma analitico de John Wilkins": os percursos enunciativos constroem categorias incongruentes e geram um artefato cuja relação com a realidade é de segundo grau, mediatizada através da linguagem. Em outras palavras, um simulacro.

Deve-se salientar também o diferente estatuto da memória no textoarquivo e no texto autobiográfico: naquele, trata-se de um processo de "salvar" (em sentido técnico) uma base documental em que os dados constituem algo exterior à experiência do narrador. Não se configura o trabalho de tecelagem de experiências passadas, em tensão com a urdidura do esquecimento, resultando na tessitura verbal. Na narrativa memorialista o "sujeito-objeto da lembrança" (Miranda: 1992,120), tomado pelo desejo da reminiscência, reinventa o passado e descobre-se a si mesmo e ao Outro, operando com a memória e a imaginação. A instância narrativa se vale da linguagem com instrumento socializador do processo de autodescoberta. Porém, no arquivo pós-moderno no hay memoria propia ni recuerdo verdadero: todo pasado es incierto y es impersonal (Piglia: 1991, 65).

Nesse exercício de memoria ajena (idem ibidem, 64), as linhas de fuga e os núcleos provisórios de sentido formados pelo leitor compõem agenciamentos: a conexão entre fragmentos da memória cultural se estabelece em proliferação e disseminação.

Tal operação, por sua vez, retoma a modelização - um modo de configuração de dados estabelecida com o suporte da eletrônica, e que implica a simulação como um tipo de construção da realidade. Além disso, tal modalidade de escrita constitui também uma reelaboração da imagem televisiva, gerada mediante o controle remoto na operação de zapping, e dialoga com as configurações imagéticas instauradas de modo análogo no videoclipe, no videogame e no computador, nesse último caso construídas com o apoio de programas de hipertexto: os links estabelecidos pelo leitor entre os fragmentos do texto colocam-se em interlocução com a sucessão de janelas que se abrem na tela de um computador quando essa tecnologia de comunicação e de informação está em funcionamento.

Ao compor a "trama do arquivo" (Miranda: 1995), o leitor interrompe uma seqüência para estabelecer conexões com outras. Mescla referências situadas em diversas localizações temporais impregnando a enunciação com a des-historicização 


\section{EM TESE}

Belo Horizonte, v. 8, p. I-243, dez. 2004

e com a redução ao plano da contemporaneidade e da simultaneidade que marcam o consumo simbólico do homem contemporâneo. Em outras palavras, o construto exibe a "saturação histórico-cultural" (Miranda: 1996,16) como traço do ethos pós-moderno.

A vertente da prosa literária em interlocução com o aparato eletrônico evidencia, também, um freqüente diálogo com o cinema. Tal como se pode observar nos textos de Thomas Pynchon, entre outros autores contemporâneos, a narração é não só permeada pela visibilidade, mas, diferentemente do delineamento moderno, se desenvolve mediante configurações imagéticas difusas. Em 0 arco-íris da gravidade o narrador chega a se subtrair da matéria narrada: assume um estatuto maquínico em termos das operações de registro ou de projeção de um filme, o que é apoiado por enunciados auto-referenciais e por citações da memória desse meio técnico de produção e reprodução de imagens. Tais estratégias, instauradoras da convergência entre o registro cinematográfico e o literário, são também fatores da construção do simulacro de um filme.

Tal plasticidade, aliada à intensa mobilização de recortes da memória cultural, constitui a base para a tese defendida por Craig Owens de que o texto pósmoderno é calcado na alegoria. Nessa linha, o teórico norte-americano se vale da análise desse tropo no drama barroco feita por Walter Benjamin (1984) para colocar, entre os procedimentos característicos do "impulso alegórico" da arte pós-moderna, a acumulação, a apropriação, e a hibridização de fragmentos de textos previamente existentes - "as ruínas" (Benjamin: 1984, 200) - que o leitor articula entre si. Cabe, pois, a essa instância uma função decisiva na produção do sentido, o que se coloca em sintonia com a arbitrariedade tradicionalmente identificada na significação alegórica. Em sua análise do tropo na escrita contemporânea, Owens examina-o em termos da ambivalência instaurada pelo leitor ao se apropriar, acumular e mesclar as fichas do material da cultura, compondo, muitas vezes, percursos incongruentes. Nesse sentido, o teórico norte-americano retoma o conceito de alegoria de Paul de Man (1979), formulado com base em passagens de Proust, Rousseau, Rilke e Nietzsche. De acordo com o filósofo da desconstrução norte-americano, o tropo se refere ao funcionamento retórico do texto literário: nele os princípios básicos de organização - os temas - são estabelecidos através de relações metafóricas, que, no entanto, são constantemente desconstruídas através de relações metonímicas. Em outras palavras, 
por causa do jogo entre metáforas e metonímias na base do texto, os percursos enunciativos são submetidos a duas leituras perfeitamente coerentes, porém exclusivas entre si. A alegoria se refere a essa configuração textual aporética, ou seja, à "impossibilidade da leitura" (1979: 233). Estendendo essa análise à escrita contemporânea, a alegoria pós-moderna, construída com base em referências culturais, tem a ver com o fato de o leitor, ao articulá-las, instaurar fios de sentido incongruentes entre si, compondo temas cuja significação é instável, sempre diferida.

Tal abertura de sentido pode ser analisada em termos da presença e da perda da aura, como se sabe, a categoria central da análise de Walter Benjamin sobre a interlocução entre a obra de arte e o desenvolvimento tecnológico. Para o filósofo alemão, a aura é uma "figura" (Benjamin: 1993, 170) instaurada pela "dimensão orgânica" (Benjamin: 1993, 117) da obra tradicional. Ou seja, a organicidade, garantia da emergência da aura, tem a ver com o regime de representação: a obra de arte tradicional mantém uma relação transparente e imediata, com a realidade. Porém, no texto sobrecarregado por referências culturais da contemporaneidade, a representação é desconstruída: o leitor conecta fragmentos de saberes que compõem um artefato com existência mediatizada em relação à realidade. A escrita do arquivo constitui o modo atual de ocorrência da "dimensão arbitrária e construtiva" (Benjamin: 1993: 117) da arte na era da máquina. O texto-arquivo, regido pela simulação, constitui o modo contemporâneo de montagem. Em termos benjaminianos, pauta-se pela perda da aura.

Observa-se, porém, que, ao articular os segmentos narrativos e as referências culturais, o leitor constrói uma aparência de relato: nos percursos de sentido, móveis e cambiantes, e apreende os posicionamentos estéticos e políticos do autor. Em outras palavras, o funcionamento textual exibe traços de organicidade, de representação - ou seja, da aura. Em termos da análise de Craig Owens, na escrita pós-moderna, o impulso alegórico caminha em direção à simulação e mina a representação, que, no entanto, emerge por resíduos nesse processo. Os dois regimes se afirmam e se negam simultaneamente: há um jogo entre eles.

Tal como evidenciam os textos de Thomas Pynchon e de Ricardo Piglia, o autor pós-moderno tende a estabelecer uma relação irônica com o Belo. Freqüentemente celebra, através de um construto de significação insólita e incongruente, uma 


\section{EMTESE}

Belo Horizonte, v. 8, p. I-243, dez. 2004

elevada concepção da obra de arte apresentada como um artefato cuja construção, ao promover a transfiguração da realidade, constitui uma forma de afirmação existencial do homem, contrapondo-se à sua fragilidade.

Além dessa modalidade de incursão no campo da estética, o texto contemporâneo constrói se em torno de outros temas. Entre eles, a contraposição ao Estado tecnocrático, no qual são identificadas redes de poder desterritorializadas com alcance planetário. Ao investir contra os efeitos da globalização, como destaca Alberto Moreiras, (2000: 81) a escrita freqüentemente critica a modernização como paradigma global dominante por séculos na história ocidental: salienta, então, aspectos como a destruição dos ecossistemas, a espoliação dos recursos materiais do planeta e as migrações da ordem pós-colonial, com grupos à margem da melhoria e do progresso.

Outro tipo de tematização decorre do diálogo estabelecido entre o texto pós-moderno e a história. Vista em termos da prática historiográfica de orientação pós-estruturalista, que tenta identificar os quatro modos - os tipos possíveis de "estruturações pré-genéricas" (White: 1994) pelos quais a massa de fatos é moldada em uma história graças ao exercício da "imaginação construtiva" (White: 1994, 98) - a escrita do arquivo como narrativa histórica deixa-se moldar pelo modo da sátira como efeito da saturação de referências culturais. Esse delineamento, por sua vez, implica a des-historicização - a sensação de um presente a-histórico - que preside à leitura. Tal perda de historicidade, por sua vez um traço característico do quadro da pós-história - conceito formulado por Arnold Gehlen (Vattimo: 1987,12-17) - está estreitamente ligada com os fluxos de mensagens em circulação no espaço social contemporâneo. Como efeito, gera-se uma modalidade de narrativa histórica também sob esse aspecto regida pela simulação, e cujo tratamento implica a ruptura com a causalidade, a linearidade e a orientação teleológica do método historiográfico oitocentista.

Observa-se que, apesar da indecidibilidade representacional característica da escrita pós-moderna, tal como a de Thomas Pynchon, Ricardo Piglia, Salmon Rushdie e de outros autores contemporâneos, o leitor pode, no entanto, ao ligar as citações históricas, formar percursos enunciativos que instauram a mimesis em estado residual, orientada para a crítica à história da dominação ocidental do mundo. 
Traços de representação são igualmente mobilizados na construção que a escrita faz da cultura como um espaço de representações simbólicas em que as categorias de identidade cultural emergem como formas através da tradução ou negociação do sentido. Esse processo, como destaca Homi Bhabha (2000: 64), é instaurador da diferença cultural: o entre-lugar da enunciação não somente promove a mixagem de traços das categorias referentes a gênero, classe, raça, etnia e nação, como também evidencia a ambivalência entre elas - a instabilidade que marca seu funcionamento na vida cotidiana.

Ao assim compor de modo fraturado as formas de identidade cultural, o texto constitui uma prática anti-representativa. Por exemplo, em 0 arco-íris da gravidade, a produção da cultura norte-americana ocorre mediante restos de articulações hegemônicas - as referências culturais, através das quais a múltiplas formações sociais da América circulam no espaço textual. Os Estados Unidos são gerados como uma nação, uma construção discursiva (Benedict Anderson: 1989) não pautada pela clausura: a identidade nacional emerge por traços, sem compor uma totalidade orgânica.

Em sintese, na escrita do arquivo a mimesis opera nos limites do horizonte textual, gerando um modo específico de prazer estético marcado pela ironia e pela indecidibilidade: a simulação se refaz no jogo intermitente com o apagamento da representação, cujos resíduos implicam que a busca pela totalidade da significação seja sempre diferida - continuamente frustrada.

ABSTRACT :

The paper describes aspects of the postmodern writing as an effect of the dialogue set with the technologies of communication and of information of the last decades. It also examines the ontological regime presiding over the relationship between reality and the works of art marked by the overcharge and the dissemination of cultural references.

KEY WORDS: postmodernism, cultural references, technologies of communication and information, simulation, representation. 


\section{EM TESE}

Belo Horizonte, v. 8, p. I-243, dez. 2004

\section{REFERÊNCIAS BIBLIOGRÁFICAS}

ANDERSON, Benedict. Nação e consciência nacional. Trad. Lólio Lourenço de 01 iveira. São Paulo: Ática, 1989.

BENJAMIN, Walter. Origem do drama barroco alemão. Trad. Sérgio P. Rouanet. São Paulo: Brasiliense, 1984.

BENJAMIN, Walter. Obras escolhidas; magia e técnica, arte e política. Trad. Sérgio P. Rouanet. 6. ed. São Paulo: Brasiliense, 1993.

BHABHA, Homi. O local da cultura. Trad. Eliana Lourenço de Lima Reis e Gláucia Renate Gonçalves. Belo Horizonte: Editora UFMG, 2000.

DE MAN, Paul. Allegories of Reading. New Haven e Londres: Yale University Press, 1979.

DE MAN, Paul. Alegorias da leitura. Trad. Lenita R. Steves. Rio de Janeiro: Imago, 1996.

LYOTARD, Jean François. O pós-moderno. Trad. Ricardo C. Barbosa. 3. ed. Rio de Janeiro, José 01ympio, 1988. MIRANDA, Wander Melo. Corpos escritos. São Paulo / Belo Horizonte: EDUSP/ Editora UFMG, 1992.

MIRANDA, Wander Melo. Pós-modernidade e tradição cultural. In: CARVALHAL, Tânia F. O discurso crítico na América Latina. Porto Alegre: Instituto Estadual do Livro/ Ed. UNISINOS, 1996. p. 13-22.

MIRANDA, Wander Melo. (Org.). A trama do arquivo. Belo Horizonte: Editora UFMG, 1995.

MOREIRAS, Alberto. A exaustão da diferença. Trad. Eliana Lourenço de Lima Reis e Gláucia Renate Gonçalves. Belo Horizonte: Editora UFMG, 2001.

OWENS, Craig. Beyond Recognition. Berkeley: University of California Press, 1992.

PIGLIA, Ricardo. Memoria y tradición. In: CONGRESSO DA ABRALIC, 2,1990. Anais... Belo Horizonte: Associação Brasileira de Literatura Comparada, 1991. p. 60-66.

VATtimo, Gianni. O fim da modernidade. Trad. Maria da Fátima Boa Vida. Lisboa: Presença, 1987.

WHITE, Hayden. Trópicos do discurso. Trad. Alípio C. F. Neto. São Paulo: EDUSP, 1994. 